\title{
Chemical Characterization of Green Coffee Beans and Determining the Effect of Roasting Temperature on the Content of Caffeine
}

\author{
Enyew A. Bayle Dagne Bayih Adamu \\ College of Natural and Computational Sciences, Debre Markos University, P.O.Box 269, Debre Markos \\ Ethiopia
}

\begin{abstract}
Coffee is one of the most popular drinks in the world. The quality of coffee depends on post harvesting process, agricultural practices, agro ecology conditions and chemical composition of coffee beans. Hararghe is among the major coffee producing areas in Ethiopia. However, the chemical profiles of Hararghe coffee beans have never been reported. The objectives of the present study was to determine $\mathrm{pH}$ value, total acidity and total polyphenols of Hararghe green coffee beans and also evaluates the effect of roasting temperature on caffeine content. Fifteen coffee bean samples were collected from different areas of Hararghe, Ethiopia. Total polyphenols were determined using the Folin-Ciocalteu reagent. The $\mathrm{pH}$ value was measured by a $\mathrm{pH}$ meter. The total acidities were determined by titrating with $\mathrm{NaOH}$. The caffeine content from roasted coffee beans was measured using a UV-Vis spectroscopy. The lowest (5.26) and the highest (5.66) $\mathrm{pH}$ values showed by the coffee bean samples collected from Jarso and Gurachae, respectively. On the contrary, the lowest $\left(1.44 \mathrm{ml}\right.$ of $\left.\mathrm{NaOHg}^{-1}\right)$ and highest $\left(2.3 \mathrm{NaOHg}^{-}\right.$ $\left.{ }^{1}\right)$ total acidity values revealed by Gurache and Jarso coffee green beans, respectively. Likewise, the lowest and the highest total polyphenols content exhibited by Girawa (7.22 mg GAE/g) and Kobo (20.96 mg GAE/g) coffee beans, respectively. The caffeine content in coffee bean samples roasted at different temperatures varied from 2.36 $(\mathrm{w} / \mathrm{w} \%)$ to $6.09(\mathrm{w} / \mathrm{w} \%)$. The content of caffeine increased from low temperature - long ranged time roasted coffee beans to intermediate temperature - intermediate ranged time. However, it was gradually decreased from intermediate temperature - intermediate ranged time to high temperature - short ranged time.
\end{abstract}

Keywords: Coffee, Caffeine, UV-Vis spectroscopy, total acidity, total polyphenols.

DOI: $10.7176 / \mathrm{CMR} / 11-8-03$

Publication date:October $31^{\text {st }} 2019$

\section{Introduction}

Coffee is highly traded commodity next to petroleum with enormous commercial and social importance [1]. Coffee Arabica and Coffee Robusta are the two species that have the highest economic importance in the world [2,3]. Both species are used as a rich source of bioactive compounds [4]. Arabica coffee beans, which originated in Ethiopian highlands, are more expensive and valuable due to their superior quality and taste. [2].

Besides, the difference in species the preference of a certain type of coffee beans over the other depends on post harvesting process conditions, agricultural practices and geographical origin (agro-ecology) and the chemical composition of coffee beans [5,6]. Green coffee beans contain a wide range of different chemical compounds and have complex compositions [7]. However, the chemical composition of green coffee beans plays a major role in defining the quality of coffee $[6,8]$. Acidity is an important feature of coffee. Citric, malic, chlorogenic and quinic acids are the main acids found in green coffee beans $[9,10]$. The antiviral and antibacterial properties of coffee may have arisen from caffeic acid, chlorogenic acid and protocatechnic acid [11]. The acidity and sourness of coffee brews (together with aroma and bitterness) have always been recognized as an important attributes of their sensory quality [12]. Polyphenols are also the chemical constituents of coffee that affects its quality [13, 14]. Coffee is the most consumable source of polyphenols [15]. Polyphenols are compounds possessing several hydroxyl groups attached with aromatic rings. They are the most abundant secondary metabolites of plants with more than 8,000 phenolic structures $[10,14]$. Polyphenols become the interested areas of research over the past years due to their antioxidant properties and their probable role in the prevention of various diseases associated with oxidative research like cancer, cardiovascular and neurodegenerative disease [10, 16]. Therefore, it is important to determine the contents of coffee beans.

Moreover, caffeine is one of the important components of coffee beans which used to characterize the quality of coffee. Caffeine is a xanthine derivative known to stimulate the central nervous system and causes various physiological effects like the relaxation of the bronchial muscle, gastric acid secretion and dieresis [17, 18]. However, high dose may produce negative effects in some sensitive individuals such as anxiety, tachycardia, restlessness, excitement, and insomnia [19, 20, 21]. Coffee is one of the most common sources of caffeine [22]. It is important to determine the amount of caffeine in coffee beans due to its widespread consumption and its physiological effect $[6,23]$. One of the factors that affect the amount of caffeine in coffee is the roasting temperature. Roasting is the most important process in coffee preparation because the beans undergo a serious of 
reactions leading to the change in physical properties and chemical compositions [7, 24]. The control of the bean temperature - time history is required during the roasting process to produce the desired coffee flavor which is influenced by the content of caffeine [25]. Various studies reported that the content of caffeine has a direct relationship with the roasting temperatures [26]. On the contrary, other studies reported that the content of caffeine decreases as roasting temperature increases [7]. Therefore, it is important to determine the effect of roasting temperature on the content of caffeine in coffee beans.

Due to its wide spread of consumption of coffee and its physiological effects, it is important to determine the chemical characteristics of coffee beans. Haraghe is among the major coffee growing regions in Ethiopia. Green coffee beans collected from different areas of Hararghe are the most expensive and preferred for consumption in Ethiopia. The content of caffeine in green coffee beans of Hararghe has been reported. However, the chemical compositions and the effect of roasting temperature on the content of caffeine of Hararghe green coffee beans have never been reported. Therefore, the aim of the present study was to determine the $\mathrm{pH}$ value, total acidity and total polyphenols of Hararghe green coffee beans and to evaluate the effect of roasting temperature on the caffeine content. The $\mathrm{pH}$ values of the extractives were measured and the total acidities of the coffee samples were determined using acid base titration method. The total poly phenols were determined using the Folin-Ciocalteu reagent. The green coffee bean samples were roasted at $125{ }^{\circ} \mathrm{C}, 175{ }^{\circ} \mathrm{C}$, and $225{ }^{\circ} \mathrm{C}$ and caffeine content was measured using a UV-Vis spectroscopy.

\section{Materials and Methods}

\subsection{Materials}

\subsubsection{Chemicals and Samples}

Caffeine standard (98\%, Loba Chemie, India), Dichloromethane (98\%, Loba Chemie, India), ethanol (97\%, fine chemical, Ethiopia), Methanol (99.5\%, Loba Chemie, India), Gallic acid (99\%, Sigma-Aldrich, Chemical Co. (St. Louis MO), USA) and distilled water (Haramaya University, Ethiopia) were used. A total of fifteen Arabica coffee beans were collected from different parts of Hararghe regions, Ethiopia. The coffee bean samples were collected from Chiro (Dingetie and Gewugewu), Diredawa, Girawa, Goromute, Gurachae, Harar (Harar Aboker, Harar Zuria 1 and Hrara Zuria 2), Hirna (Hirna Zuria 1 and Hirna Zuria 2), Jarso, Kobo, Kurfachele, and Lange. The coffee beans samples were labeled based on the name of the collection areas.

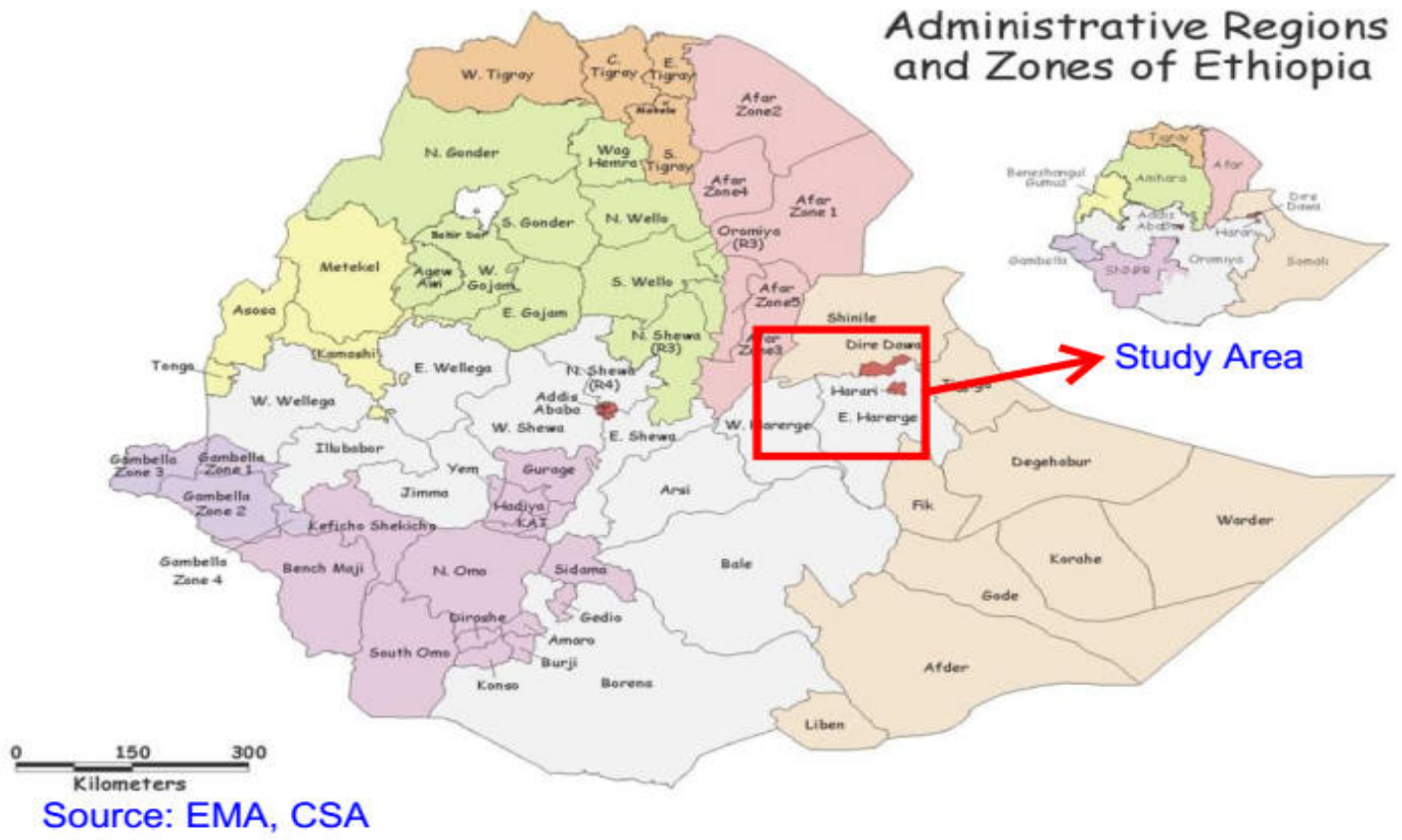

Figure: Sample Collection Sites, Hararghe, Oromia Regional State, Ethiopia

\subsubsection{Instrumentation}

Different laboratory apparatus were used and a double-beam spectrophotometer (Lambda 9-UV/Vis/NIR, PerkinElmer, USA) with $1 \mathrm{~nm}$ resolution in a $1 \mathrm{~cm}$ path length quartz cell was used to obtain all the absorption spectra. The spectra were obtained by computer interfaced with a spectrometer. 


\subsection{Methods}

\subsection{1. pH Measurement}

The $\mathrm{pH}$ was estimated by preparing extractives with ground coffee $(3 \mathrm{~g})$ in $50 \mathrm{~mL}$ of hot water [27]. The extract was cooled to room temperature and $\mathrm{pH}$ of the extractives was measured using a $\mathrm{pH}$ meter after it was calibrated according to the manufacturer.

\subsubsection{Total Acidity}

The total acidity in the coffee samples was estimated by treating $10 \mathrm{~g}$ coffee sample in an Erlenmeyer flask with $75 \mathrm{~mL}$ of $80 \%$ alcohol, stopper it and stayed for $16 \mathrm{hr}$ with occasionally shaking and then filtered and transferred $10 \mathrm{~mL}$ of filtrate to a beaker. The filtrate was diluted to $100 \mathrm{~mL}$ with water and titrated with $0.1 \mathrm{~N} \mathrm{NaOH}$ using phenolphthalein as an indicator [27]. The results were expressed as $0.1 \mathrm{~mL}$ alkali required neutralizing acidity of $100 \mathrm{~g}$ sample.

\subsubsection{Total Polyphenols}

The Folin-Ciocalteu phenol reagent was prepared by dissolving $10 \mathrm{~g}$ sodium tungstate and $2.5 \mathrm{~g}$ sodium molybdate in $70 \mathrm{~mL}$ distilled water. Five $\mathrm{mL} 85 \%$ phosphoric acid and $10 \mathrm{~mL}$ concentrated hydrochloric acid was added to the above solution and refluxed for $10 \mathrm{hr}$. Then $15 \mathrm{~g}$ lithium sulfate, $5 \mathrm{~mL}$ water and 1 drop bromine solution was added to the solution and refluxed for 15 minutes. The solution was cooled to room temperature and brought to $100 \mathrm{~mL}$ with distilled water.

Standard solutions of Gallic acid $(10,20,30,40$ and $50 \mathrm{ppm})$ were prepared in methanol for calibration curve. One $\mathrm{mL}$ of these solutions was added to a $25 \mathrm{~mL}$ volumetric flask containing $9 \mathrm{~mL}$ of distilled water. One milliliter of Folin-Ciocalteu phenol reagent was added to the mixture and shaken. After $5 \mathrm{~min}, 10 \mathrm{~mL}$ of a $7 \%$ sodium carbonate solution was added with mixing. The solution was then immediately diluted to a volume of $25 \mathrm{~mL}$ with distilled water and mixed thoroughly. After incubation for $90 \mathrm{~min}$ at room temperature, the absorbance at $765 \mathrm{~nm}$ was measured. Ground coffee $(2 \mathrm{~g})$ was dissolved in $30 \mathrm{~mL}$ methanol in the flask and placed it in the arbitrary shaker for $1 \mathrm{hr}$ at $40{ }^{\circ} \mathrm{C}$ in order to get methanol extract. After sample preparation, $1 \mathrm{~mL}$ of appropriately diluted samples was added to a $25 \mathrm{~mL}$ volumetric flask contained $9 \mathrm{~mL}$ of distilled water. A blank reagent was prepared using distilled water. One milliliter of Folin-Ciocalteu phenol reagent was added to the mixture and shaken. After $5 \mathrm{~min}, 10 \mathrm{~mL}$ of $7 \%$ sodium carbonate solution was added with mixing. The solution was then immediately diluted to a volume of $25 \mathrm{~mL}$ with distilled water and mixed thoroughly. After incubation for $90 \mathrm{~min}$ at room temperature, the absorbance at $765 \mathrm{~nm}$ was measured $[9,28]$. The total phenolic contents of the samples were expressed in milligrams per serving of Gallic acid equivalents (GAE).

\subsubsection{Influence of roasting temperature on caffeine content}

\subsubsection{Standard solution preparation}

From the standard of pure caffeine $2.5 \mathrm{mg}$ was dissolved into $50 \mathrm{~mL}$ of de-ionized water. Then $25 \mathrm{~mL}$ of the caffeine stock solution was further diluted with distilled water into different concentrations using four volumetric flasks. These solutions were stirred with a magnetic stirrer for 30 minutes. The absorbencies of the solutions were measured using UV-Vis spectrometer. These procedures were repeated three times for similar concentrations. The mean values of the absorbencies were taken and used for the preparation of the calibration curve so as to determine caffeine from the roasted coffee bean samples.

\subsubsection{Roasting of coffee beans}

Five different coffee bean samples were roasted at $125{ }^{\circ} \mathrm{C}, 175{ }^{\circ} \mathrm{C}$, and $225{ }^{\circ} \mathrm{C}$. The coffee samples were roasted using a hot plate and a digital thermometer to control the temperature variation.

\subsubsection{Liquid-liquid Extraction of caffeine}

Roasted coffee bean samples were grounded and screened through $250 \mu \mathrm{m}$ sieve to get a uniform texture. Approximately $50 \mathrm{mg}$ of sieved coffee was dissolved in $25 \mathrm{~mL}$ distilled water. The solution was stirred for one hour using magnetic stirrer and heated gently $\left(60{ }^{\circ} \mathrm{C}\right)$ to remove caffeine easily from the solution. The solution was filtered by a centered glass filter to get rid of particle from solution. The solution was mixed with dichloromethane by volume ratio $(25: 25 \mathrm{~mL})$ for the extraction of caffeine from coffee. First, a mixture of the solution was stirred for $10 \mathrm{~min}$. Then, using separatory funnel caffeine was extracted by dichloromethane from the solution. The extraction of caffeine was preceded 4 times with $25 \mathrm{~mL}$ dichloromethane at each round. The caffeine extracted by dichloromethane at each round was stored in volumetric flasks. Finally, the absorbance of the solution was measured by UV/Vis spectrophotometer in the range of 200-360 nm against the corresponding reagent blank [29].

\section{Results and Discussion}

This study presents the $\mathrm{pH}$ values, total acids and total polyphenols of fifteen green coffee bean samples collected from various areas of Harargae, Ethiopia. In addition, it also explains the effect of roasting temperature on caffeine content for five coffee samples arbitrary selected from the above mentioned location. 


\section{1. pH Measurement}

The $\mathrm{pH}$ values of the coffee samples ranges from 5.26 to 5.66 as shown in Fig 1. The lowest and the highest $\mathrm{pH}$ values are shown by the coffee bean samples collected from Jarso and Gurachae, respectively. The data revealed that Jarso coffee beans are the most acidic and Gurachae coffee beans are the least acidic. Acidity is one of the attributes commonly associated with high quality coffees. Many researchers observed a linear correlation between the $\mathrm{pH}$ value and the perceived acidity of coffee [30].

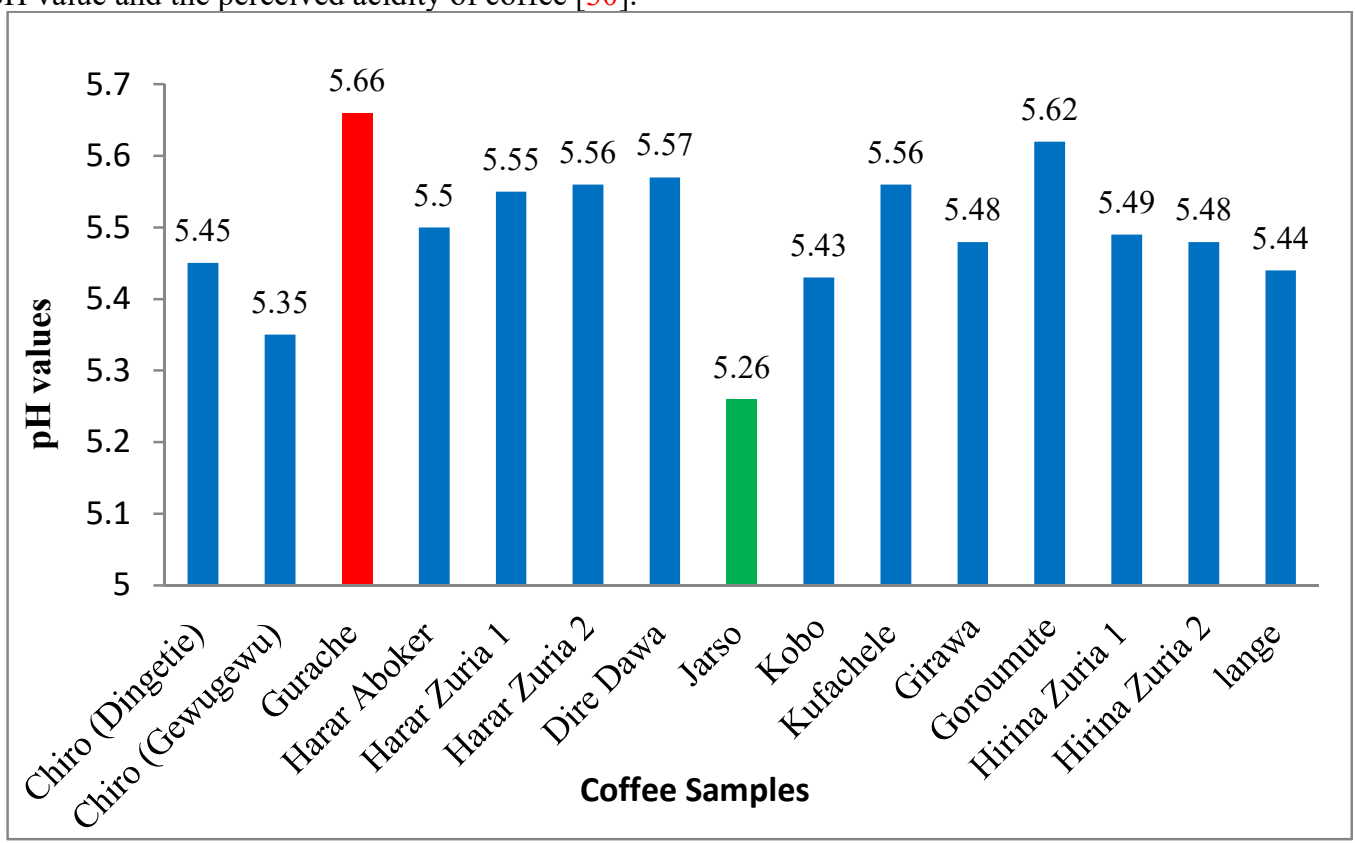

Figure 1. Variations of $\mathrm{pH}$ values among coffee bean samples

\subsection{Total Acidity}

Recent findings showed that undissociated, which are not described in $\mathrm{pH}$ variation, forms of acid molecules are important for acid perception. Therefore, the amount of titratable acidity could be more reliable indicator for correlating the coffee acidity than $\mathrm{pH}$ value [31]. The total acidity values of the samples ranges from 1.44 to 2.3 $\mathrm{ml} \mathrm{NaOH} . \mathrm{g}^{-1}$ as shown in Fig. 2. The lowest and the highest total acidity values are shown by the coffee bean samples collected from Jarso and Gurachae, respectively. The result shows that Jarso is least acidic and Gurachae is most acidic coffee samples which coincides with the results obtained from $\mathrm{pH}$ values. 


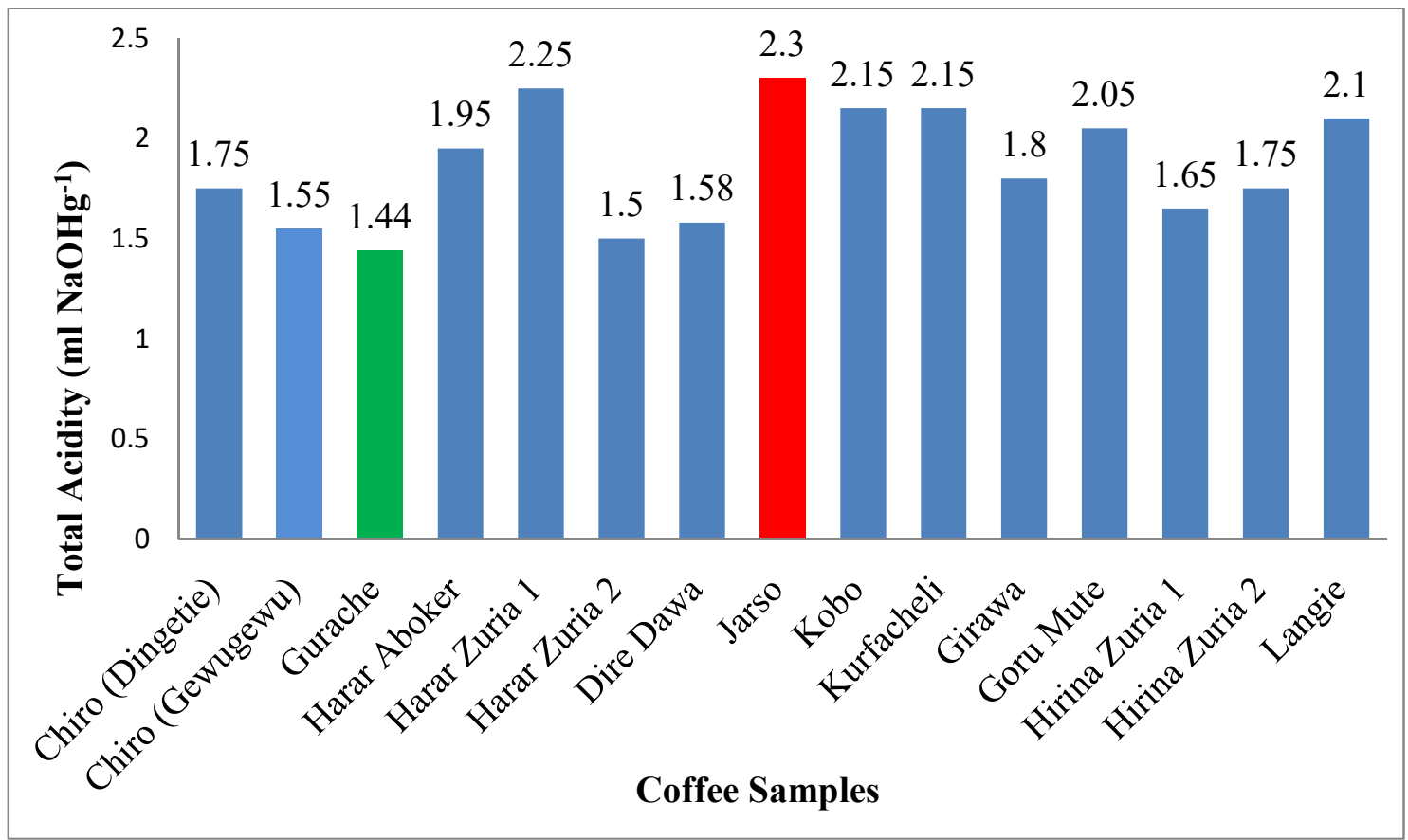

Figure 2. The total acidity of the coffee samples expressed in $\mathrm{mL}$ of $\mathrm{NaOH} \cdot \mathrm{g}^{-1}$.

\subsection{Total Polyphenols}

The total phenol contents in green coffee beans were determined using the Folin-Ciocalteu colorimetric method in terms of gallic acid equivalents (GAE). The absorbencies of the Gallic acid standards were used to develop the calibration curve (Figure 3). The value of the square of the regression coefficient $\left(R^{2}=0.9998\right)$ showed a good relationship and is convenient to determine the total polyphenols from coffee beans.

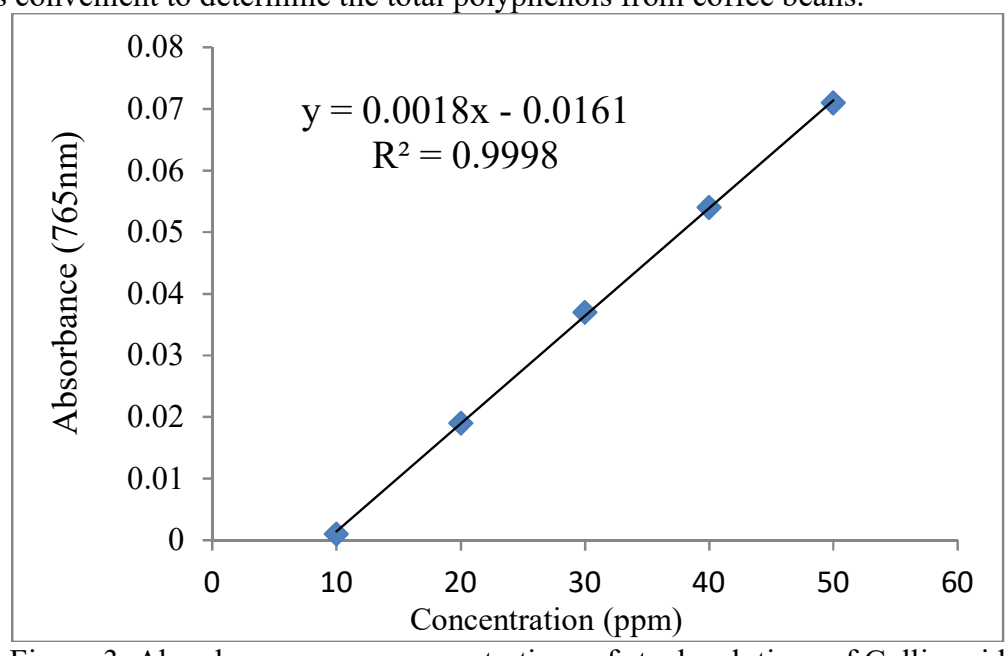

Figure 3. Absorbance versus concentrations of stock solutions of Gallic acid

The total polyphenols contents in green coffee beans are varied from $7.22 \pm 0.022$ to $20.96 \pm 0.012 \mathrm{mg} \mathrm{GAE} / \mathrm{g}$ (Table 1). The lowest and highest total phenol contents were observed in Girawa and Kobo green coffee bean samples, respectively. 
Table 1: Total phenol contents in green coffee beans

\begin{tabular}{|l|c|l|c|}
\hline Coffee Samples & $\begin{array}{l}\text { Total phenol contents } \\
((\mathrm{mg} \text { GAE/g) mean } \pm \text { SD }))\end{array}$ & Coffee Samples & $\begin{array}{l}\text { Total phenol contents } \\
((\mathrm{mg} \text { GAE/g) mean } \pm \text { SD })\end{array}$ \\
\hline Chiro (Dingetie) & $16.89 \pm 0.012$ & Harar Zuria 2 & $9.74 \pm 0.014$ \\
\hline Chiro (Gewugewu) & $8.56 \pm 0.008$ & Hirna Zuria 1 & $13.56 \pm 0.010$ \\
\hline Diredawa & $14.40 \pm 0.014$ & Hirna Zuria 2 & $13.35 \pm 0.009$ \\
\hline Girawa & $7.22 \pm 0.022$ & Jarso & $13.36 \pm 0.015$ \\
\hline Goroumute & $8.15 \pm 0.015$ & Kobo & $20.96 \pm 0.012$ \\
\hline Gurachae & $10.20 \pm 0.009$ & Kurfacheli & $14.60 \pm 0.006$ \\
\hline Harar Aboker & $17.94 \pm 0.010$ & Langie & $17.25 \pm 0.005$ \\
\hline Harar Zuria 1 & $18.36 \pm 0.013$ & \multicolumn{2}{|c}{} \\
\hline
\end{tabular}

\subsection{Influence of roasting temperature on the content of caffeine}

A total of five coffee samples were roasted at $125{ }^{\circ} \mathrm{C}, 175{ }^{\circ} \mathrm{C}$ and $225{ }^{\circ} \mathrm{C}$ to observe the effect of temperature on the content of caffeine. Caffeine was extracted by dichloromethane from the coffee sample solutions. The extraction of caffeine was preceded 4 times with $25 \mathrm{ml}$ dichloromethane at each round. The complete extraction of the caffeine from the coffee samples was made sure by measuring the absorbance of the coffee sample solutions after the first, second, third and fourth rounds of extraction. The absorbance of the coffee sample solutions obtained from the fourth round extraction was in a negligible amount.

The contents of caffeine in the roasted coffee beans were determined from calibration curve (Figure 4). The calibration curve was developed from the absorbencies of different concentrations of the caffeine standards. The value of the square of the regression coefficient $\left(R^{2}=0.9965\right)$ showed a good relationship and is convenient to determine the content of caffeine from coffee beans.



Figure 4: Absorbance versus concentration of the caffeine standard

Table 2 provides the caffeine content from the roasted coffee beans which were determined using the linear equation $(\mathrm{y}=1.3091 \mathrm{x}+0.0226)$ obtained from the calibration curve.

Table 2: The content of caffeine in different coffee bean samples roasted at 125,175 , and $225^{\circ} \mathrm{C}$.

\begin{tabular}{|c|c|c|c|}
\hline \multirow{2}{*}{ Coffee Samples } & \multicolumn{3}{|c|}{$\begin{array}{c}\text { Percentage of caffeine (w/w \%) at different } \\
\text { temperatures (mean } \pm \text { SD) }\end{array}$} \\
\cline { 2 - 4 } & $\mathbf{1 2 5}^{\mathbf{0}} \mathbf{C}$ & $\mathbf{1 7 5}^{\mathbf{}} \mathbf{C}$ & $\mathbf{2 2 5}^{\mathbf{0}} \mathbf{C}$ \\
\hline Chiro (Dingetie) & $2.95 \pm 0.008$ & $3.60 \pm 0.024$ & $3.25 \pm 0.022$ \\
\hline Dire Dawa & $3.81 \pm 0.003$ & $6.09 \pm 0.016$ & $4.22 \pm 0.032$ \\
\hline Harar Aboker & $2.36 \pm 0.042$ & $4.82 \pm 0.006$ & $4.93 \pm 0.008$ \\
\hline Harar Zuria 2 & $2.59 \pm 0.030$ & $3.30 \pm 0.012$ & $2.95 \pm 0.046$ \\
\hline Hirina Zuria 1 & $3.01 \pm 0.006$ & $3.54 \pm 0.008$ & $3.16 \pm 0.018$ \\
\hline
\end{tabular}

The caffeine content in coffee bean samples roasted at different temperatures ranges from $2.36(\mathrm{w} / \mathrm{w} \%)$ to $6.09(\mathrm{w} / \mathrm{w} \%)$, Table 2. It was reported that the caffeine content in these green coffee bean samples were varied from $0.60820 \pm 0.00277$ to $0.90285 \pm 0.00601(\mathrm{w} / \mathrm{w} \%)$ [32]. The results of the present study revealed that the caffeine content increased from low temperature - long ranged time roasted coffee beans to intermediate temperature - intermediate ranged time. However, it was gradually decreased from intermediate temperature - 
intermediate ranged time to high temperature - short ranged time. Our result is in line with different studies reported that the content of caffeine increase during roasting process and start to decrease as the temperature further increases [26]. On the contrary, there are some reports that show the content of caffeine reduced during the roasting process unlike the results of the present study [7].

\section{Conclusion}

The results of the present study provided a detail overview of $\mathrm{pH}$ values, total acidity and total polyphenols, as well as the effect of roasting temperature on the content of caffeine. The results revealed that $\mathrm{pH}$ values, total acidity and total polyphenols of different green coffee beans vary depending on the area where the green coffee beans were collected. Moreover, the results exhibited that the content of caffeine in roasted coffee beans is affected by the roasting temperature. The data collected from both $\mathrm{pH}$ and total acidity measurement revealed that coffee beans collected from Jarso are the most acidic while coffee beans collected from Gurache are the least acidic. However, the lowest and highest total phenol contents were observed in Girawa and Kobo green coffee bean samples, respectively. Moreover, the result revealed that the content of caffeine increased from low to intermediate temperatures and fall back at higher temperatures.

\section{Acknowledgment}

The authors would like Haramaya University for the financial support and Chemistry department of Haramaya University for providing laboratory rooms and meterials.

\section{Competing Interests}

The authors declare that there are no competing interests regarding the publication of this paper.

\section{References}

1. Pizzariello A., Svorc J., Stredansky M., Miertus S. (1999). A biosensing method for detection of caffeine in coffee. J Sci Food Agric, 79: 1136 - 1140 .

2. Illy E. (2002). The complexity of Coffee. Scientific American, 86 - 91.

3. FAS/USDA (2013). Coffee: world markets and trade office of global analysis, foreign agricultural service/united states department of agriculture.

4. Minamisawa M., Yoshida S. \& Takai N. (2004). Determination of biologically active substances in roasted coffees using a diode-array HPLC system. Analytical science, 20: 325 - 328.

5. Andriot I., Le Quere J.-L. \& Guichard E. (2004). Interaction between coffee melanoidins and flavor compounds: impact of freeze-drying (method and time) and roasting degree of coffee on melanoidins retention capacity. Food Chemistry, 85 (2): 289 - 294.

6. Hecimovic I., Belscak-Cvitanovic A., Horzic D., Komes D. (2011). Comparative study of polyphenols and caffeine in different coffee varieties affected by the degree of roasting. Food chemistry, 129: 991-1000.

7. Franca S.A., Mendonca J.C.F., Oliveria S.D. (2005). Composition of green and roasted coffees of different cup qualities. LWT-Food Science and Technology, 38 (7): $709-715$.

8. Belay A. (2011). Some biochemical compounds in coffee beans and methods developed for their analysis. Int. J. Phys. Sci., 6 (28): $6373-6378$.

9. Butt M.S., Ahmed A., Sultan M.T., Imran A., Yasin M., Imran M. (2011). Evaluating the effect of decaffeination on nutritional and antioxidant status of different coffee brands. Internet Journal of Food Safety, 13: $198-207$.

10. Manach C., Scalbert A., Morand C., Remesy C., Jimenez L. (2004). Polyphenols: food sources and bioavilability. Am. J. Clin. Nutr, 79: $727-747$.

11. Camergo MCR and Toledo MCF. (1998). Caffeine content of commercial Brazilian coffee. Cienc Technol Aliment, 18: $421-424$.

12. Dogasaki C., Shindo T., Furuhata K., Fukuyama M. (2002). Identification of chemical structure of antibacterial components against Legionella pneumophilia in a coffee beverage. Yakugaky Zasshi, 122: 487 $-494$.

13. Belay A., Gholap A.V. (2009). Characterization and determination of Chlorogenic acids (CGA) in coffee beans by UV-Vis spectroscopy. African Journal of Pure and Applied Chemistry, 3 (11): $234-240$.

14. Dai J., Mumper R.J. (2010). Plant phenolics: extraction, analysis and their antioxidant and anticancer properties. Molecules, 15: 7313 - 7352.

15. Ovaskainen M.L., Torronen R., Koponen J.M., Sinkko H., Hellstrom J. Reinivuo H., Mattila P. (2008). Dietary intake and major food sources of polyphenols in Finnish adults. J Nutr, 138 (3): 562 - 566.

16. Scalbert A., Manach C., Morand C., Remesy C. (2005). Dietary polyphenols and the prevention of disease. Critical Reviews in food science and nutrition, 45: $287-306$.

17. Yukawa G.S., Mune M., Otani H., Tone Y., Liang X.-M., Iwahashi H., Sakamoto W. (2004). Effects of coffee 
consumption on oxidatives susceptibility of low-density lipo proteins and serum lipid level on humans. Biochemistry (Moscow), 69 (1):70 - 74.

18. Zhang Q., Lian H., Wang W., Chen H. (2005). Separation of caffeine and theophylline in poly (dimethylsiloxane) microchannel electrophoresis with electrochemical detection. J. Chromatogr, 1098: 172 176.

19. Nehlig A. (1999). Exploring biotechnology. ChemTech, 29 (7): 30 - 35.

20. Ogita S., Uefugi H., Yamaguchi Y., Koizumi N., Sano H. (2003). Producing decaffeinated coffee plants. Nature, 423 (6942) $823-\mathrm{x}$.

21. Ramalakshmi K., Raghavan B. (1999). Caffeine in coffee: its removal. Why and How? Critical Reviews in Food Science and Nutrition, 39 (5): 441 - 456.

22. Mumin M.A., Akhter K.F., Abedin M.Z., Hossain M.Z. (2006). Determination and characterization of caffeine in tea, coffee and soft drink by solid phase extraction and HPLC. Malaysian J. Chem., 8 (1): $045-051$.

23. Salinas-Vargas M.E., Canizares-Macias M.P. (2014). On-line solid-phase extraction using a C18 minicolumn coupled to a flow injection system for determination of caffeine in green and roasted coffee beans. Food Chemistry, 147: $182-188$.

24. De Maria C.A.B., Trugo L.c., Aquino Neto F.R., Moreria R.F.A., Alviano C.S. (1996). Composition of green coffee water-soluble fraction and identification of volatiles formed during roasting. Food Chemistry, 55 (3): $203-207$

25. Aliah A.M.N, Edzuan A.M.F., Diana A.M.N. (2015). A review of quality coffee roasting degree evaluation. J. Appl. Sci. \& Agri., 10 (7): 18 - 23.

26. Cuong T.V., Ling L.H., Quan J.K., Tiep T.D., Nan X., Qing C.X., Linh T.L. (2014). Effect of roasting conditions on several chemical constituents of Vietnam Robusta coffee. Food Technology, 38 (2): 43 - 56.

27. Mazzafera P. (1999). Chemical composition of defective coffee beans. Food Chemistry, 64: $547-554$.

28. Singleton V.L. and Rossi J. (1965). A colorimetry of total phenolics with phosphomolybdic-phosphotungstic acid reagents. Am J Enol Vitic, 16: $144-153$.

29. Belay A., Ture K., Redi M., Asfaw A. (2008). Measurement of caffeine in coffee beans with UV/Vis spectrometer. Food Chemistry, 108: $310-315$.

30. Griffin M. J. \& Blauch D. N. (1999). Determination of the relationship between phosphate concentration and perceived acidity in coffee. In $18^{\text {th }}$ International Scientific Colloquium on Coffee, $118-126$

31. Voilley A., Sauvageot F., Simatos D., Wojcik G. (1981). Influence of some processing conditions on the quality of coffee brew. J. Food Processes. Preservation, 5 (3): 135 - 143

32. Demissie G.E., Woyessa W.G., Abebe A. (2016). UV/Vis Spectrometer determination of caffeine in green coffee beans from Hararghe, Ethiopia, using Beer-Lambert's law and integrated absorption coefficient techniques. St. Cerc. St. CICBIA, 17 (2): $109-123$. 